
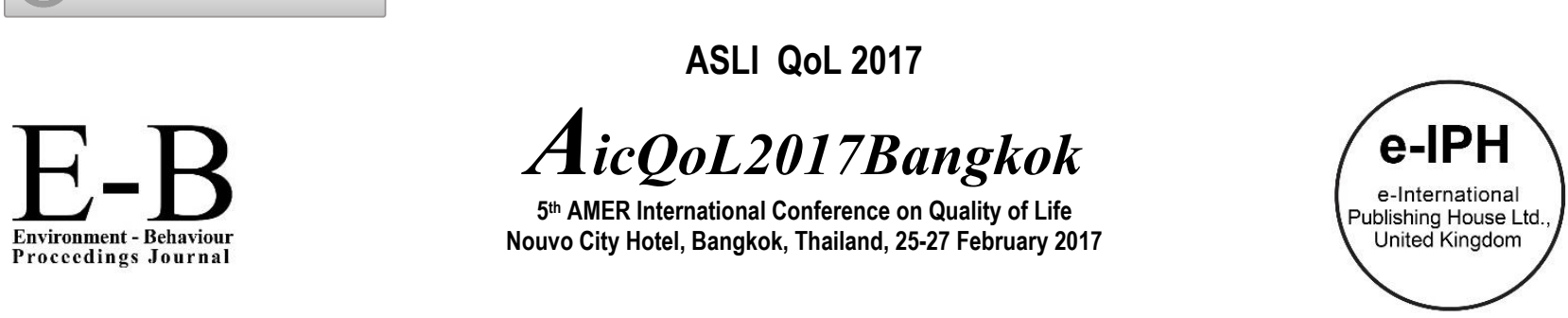

\title{
Obstacles to the Automation of Building Performance Simulation: Adaptive Building Integrated Photovoltaic (BIPV) design
}

\author{
Nuttasit Somboonwit ${ }^{1 *}$, Amon Boontore ${ }^{2}$, Yanin Rugwongwan 1 \\ ${ }^{1}$ Multidisciplinary Design Research, ${ }^{2}$ Department of Urban and Regional Planning, \\ Faculty of Architecture, King Mongkut's Institute of Technology Ladkrabang, Chalongkrung Road, Ladkrabang, Bangkok, 10520, Thailand
}

\begin{abstract}
Building Integrated Photovoltaic (BIPV) is one of the most promising renewable energy technologies. A BIPV system as a second layer of building envelopes is useful not only for the electric power generation but also for blocking solar radiation to reduce cooling load. This study aimed to explore the limitations of the automated BPS of an adaptive BIPV case study that its development conducted through a collaboration of a BIM software, a BIM-integrated visual programming environment, and a cloud-based energy analysis. The possible obstacles to BIPV design processes and the potential solutions have been discussed.
\end{abstract}

Keywords: Automated Building Performance Simulation; Adaptive Building; Building Integrated Photovoltaic; Building Information Modelling; Parametric Modelling

ISSN: 2398-4287@ 2017. The Authors. Published for AMER ABRA by e-International Publishing House, Ltd., UK. This is an open access article under the CC BYNC-ND license (http://creativecommons.org/licenses/by-nc-nd/4.0/). Peer-review under responsibility of AMER (Association of Malaysian Environment-Behaviour Researchers), ABRA (Association of Behavioural Researchers on Asians) and cE-Bs (Centre for Environment-Behaviour Studies), Faculty of Architecture, Planning \& Surveying, Universiti Teknologi MARA, Malaysia.

\subsection{Introduction}

Building Integrated Photovoltaic (BIPV) is one of the most promising renewable energy technologies that aimed to attain the integration of various types of solar photovoltaic panels into the building envelopes, such as the roofs or the facades. Building Integrated Photovoltaics (BIPV) is the integration of photovoltaics (PV) into the building envelope. The PV modules are considered as a functional part of the building structure, or they are architecturally integrated into the building's design, serve the dual function of building skinreplacing conventional building envelope materials-and power generator simultaneously. By avoiding the cost of conventional materials, the incremental cost of photovoltaics is reduced and its life-cycle cost is improved. That is, BIPV systems often have lower overall costs than PV systems requiring separate, dedicated, mounting systems (Peng, Huang, \& Wu, 2011; Strong, 2011; Jelle, Breivik, \& Røkenes, 2012). This can provide savings in materials and labour, and also reduce the electricity costs. BIPV systems are typically rooftop installations owing to the relatively heavy weight structure of traditional silicon-based PV modules (Frontini, et al., 2015; Nagy, et al., 2016). On the other hand, thin-film PV modules, such as copper indium gallium selenide (CIGS), cadmium telluride, and amorphous silicon, offer the advantage of flexible, curved, shapes and lightweight structure when compared to the traditional modules, which come at the price of lower energy conversion efficiencies (Reinhard, et al., 2013).

\subsection{Adaptive building envelopes / photovoltaic façades}

A building envelope acts as a buffer or mediator between the interior and the exterior environment. The envelope can mitigate solar insolation, thereby offering reductions in heating/cooling loads, and improve the distribution of daylight (Nagy, et al., 2016). Nowadays the increasing interest for adaptive buildings that reconfigure themselves to meet environmental mutations and users' need has driven the concept of new building skins that are multifunctional, responsive and dynamic (Pesenti, Masera, Fiorito, \& Sauchelli, 2015). Furthermore, adaptive façades are able to enhance the operational strategies of shading systems that affect not only from the thermal

\footnotetext{
${ }^{*}$ Corresponding author. Tel.: +66-81-421-8730

E-mail address: nuttasit.somboonwit@gmail.com
}

ISSN: 2398-4287@ 2017. The Authors. Published for AMER ABRA by e-International Publishing House, Ltd., UK. This is an open access article under the CC BYNC-ND license (http://creativecommons.org/licenses/by-nc-nd/4.0). Peer-review under responsibility of AMER (Association of Malaysian Environment-Behaviour Researchers), ABRA (Association of Behavioural Researchers on Asians) and CE-Bs (Centre for Environment-Behaviour Studies), Faculty of Architecture, Planning \& Surveying, Universiti Teknologi MARA, Malaysia.

DOI: http://dx.doi.org/10.21834/e-bpj.v2i5.619 
point of view (thermal comfort) but also for its visual implications. Light should be seen as necessary for vision and as a powerful modulator of non-visual functions, like the improvement of alertness and performance on cognitive tasks. Thus, occupants' visual comfort must be considered by the physiological and psychological point of view as a part of the processes used by people to improve the fit between needs and environmental conditions through adaptation to the surrounding environment that connected to the occupants' satisfaction (Fiorito, et al., 2016). A BIPV system as a second layer of building envelopes is useful not only for the electric power generation but also for blocking solar radiation to reduce cooling load. To gain more efficient of the both advantages of that BIPV systems, using adaptive kinetic PV building envelopes that capable of tracing the movement of the sun and adapting their geometries according to the solar geometry is an intriguing technology.

\subsection{Kinetic Photovoltaic Facades (KPVF)}

Shading devices are one of the building envelope components / facades suitable for the integration of renewable energy systems (Fiorito, et al., 2016). Photovoltaics as shading devices are usually an external building skin layer that can be applied independently in both new and existing buildings. This technology has dual advantage of generating electricity directly from the incident sun light and the normal function of external blinds in protecting the building from overheating, providing visually comfortable interior space and save energy (Ibraheem, Farr, \& Piroozfar, 2016). Photovoltaic facades have proven technical advantages over other types of PV installations by the higher possibilities to integrate kinetic technologies to track the sun, while acting as an interactive solution for optimising solar gain throughout the year. The design of integrated photovoltaic shading devices proposed by lbraheem, Farr, \& Piroozfar (2016) concerned of two different sub-categories i.e., design considerations and design configurations, and three levels of systems i.e., super-system level, system level, and sub-system level (Ibraheem, Farr, \& Piroozfar, 2016). Design considerations are those factors over which there would be no direct control, and where they cannot directly be changed or modified, those can include climate, site, topography, neighbouring buildings, etc. In contrast, design configurations are those elements which can be adjusted, changed or manipulated by the designer and are accounted for as a part of the project that can be shaped by the design process and/or impacted by it. Such variables include building orientation, building geometry, size and geometry of opening and their sub-elements, e.g. their location, height, shape, form, angle, etc. For the three levels of systems i.e., super-system level, system level, and sub-system level; at 'super-system' level (or the building context level); building location/latitude, climatic data (solar radiation, temperature, sky conditions, and other climatic parameters), and the effect of different surroundings. At 'system' level (of building level); building orientation, architectural functions (weather proofing, noise reduction, shading, flexibility, transparency, colour, and texture), shading coefficient and daylight factor, building types and PV solutions. And at 'sub-system' level (building façade envelope variations); the angle of inclination, the tilt angle and dimension of the PV panels, and the ratio of the distance between the modules and the depth of the modules.

In order to appropriately apply Kinetic Photovoltaic Facades (KPVF), it was essential to highlight the main influential parameters that affect the performance of the KPVF such as providing optimal tilt angle of the devices with the right size and correct distance from the glazing so that they can eliminate excessive sunlight during summer while allowing it in during winter and letting diffuse solar radiation penetrate into the building (Yoo, 2011; Ibraheem, Farr, \& Piroozfar, 2016).

\subsection{Building Information Modelling: BIM}

However, to support building designers coping with the complexity of adaptive BIPV needs processes and tools with abilities to optimise the design of kinetic PV envelopes that serve as both PV components and shading devices. Nowadays, precise information about all physical and functional characteristics of a single building can be organised in a BIM (Building Information Model). BIM is one of the most promising developments in the Architecture, Engineering, Construction, and Operations (AECO) industries. A BIM is an emerging tool / methodology / paradigm / process of virtual design and construction involving the generation and management of digital representations of physical and functional characteristics of a facility which creates and uses the coordinated, consistent, computable information of the 3D models of the project components interconnect with the holistic information that conceived as a source of shared knowledge to support decision-making, allowing better analysis and control than manual processes, about a facility from its earliest conceptual stages, through design and construction, through its operational life and eventual demolition. When completed, these computer-generated-semantic-3D models contain precise geometry and data needed to support the construction, fabrication, and procurement activities through which the building is realized (Krygiel \& Nies, 2008; Kymmell, 2008; Eastman, Teicholz, Sacks, \& Liston, 2011; Matthew, Jason, Melissa, Seokho, \& Fiona, 2013; Ladenhauf, et al., 2015; Agugiaro, 2016). Today, a number of tools exist for BIMs to estimate the global energy demand and to raise the building energy efficiency (Kumar, 2008; Kim \& Anderson, 2013)

\subsection{Parametric Modelling and Visual Programming/Scripting Interfaces}

Parametric modelling is also an important part of the BIM technology, helping to manage the relationship among building objects and to explore real-time design options. Parametric modelling enables parameters to be processed by mathematical formulas and computational algorithms before being passed among objects. To this extent, BIM-based parametric modelling can be integrated with adaptive BIPV to suggest a systematic design decision process that enables buildings to respond to specific solar geometry.

Visual programming is a concept that provides designers with the means for constructing programmatic relationships using a graphical user interfaces, rather than writing codes from scratch, and allows building designers to easily experiment with various design alternatives without professional knowledge of programming or scripting, and there exist several visual programming environments in CAD and BIM tools such as Bentley Generative Components and Grasshopper for McNeel Rhinoceros. Designers 
are able to assemble custom relationships by connecting pre-packaged nodes together to make a custom algorithm (Autodesk, 2013; Kim, Asl, \& Yan, 2015).

The Autodesk Revit API (Application Programming Interface) allows users to add to the features of the software and create custom tools and plugins. Dynamo is a plugin to Revit using the Revit API and built using the Windows Presentation Framework. As a parametric modelling engine, Dynamo takes its inspiration from other tools to extend Revit's parametric modelling capabilities by adding a level of associativity that does not exist in the off-the-shelf application including driving parameters based on external inputs, such as solar geometry (Kensek, 2014). Dynamo allows designers to design custom computational design and automation processes through a node-based Visual Programming Interface (Kron, 2013).

\subsection{Automated vs Manual BPS}

Meaningful simulation of building energy performance requires the use of contemporary sophisticated simulation software and large amounts of data. The main purpose of Building Performance Simulation (BPS) is to quantitatively justify design decisions as a result of predicting real physical conditions in a building by using a computational model, and to support building design processes by providing a high integrity representation of the dynamic, connected and non-linear physical processes that govern the disparate performance aspects that dictate overall acceptability of building and their related energy supply systems (Bazjanac, et al., 2011; Clarke \& Hensen, 2015; Shen \& Lu, 2016). While there has been good progress with fundamental process representation, this has been achieved with much duplication of effort and significant deficiencies remain (Clarke \& Hensen, 2015). An intelligent approach to better deal with these deficiencies in BPS, from the time-consuming, cumbersome and error-prone of manual data generation and use of improvised defined data that may invalidate the results, is the automation of BPS input data acquisition and transformation (Bazjanac, et al., 2011; Clarke \& Hensen, 2015) Reusing of existing data by interoperable processes would significantly reduce the time and overhead associated with the creation of simulation models (Hand, Crawley, Donn, \& Lawrie, 2005; Bazjanac, et al., 2011; O'Donnell, et al., 2011). An interoperable, intelligent and object-oriented simulation model would enable bi-directional data exchange with a Building Information Modelling (BIM) authoring applications, reusing of geometric and other data from different models significantly reduces the overhead associated with the definition of input data and has the potential to eliminate error-prone manual processes (O'Donnell, et al., 2011).

Designing an efficient building integrated photovoltaic involves elements of expertise deriving from multiple disciplines such as architects, civil, mechanical and electrical engineers (Negendahl, 2015). With numerous unified tools that act both as a design tool and BPS tool exist, building designers still seem to prefer to crate and explore design options in dedicated design tool such as ArchiCAD, Revit, SketchUp, etc., as they support the concept of a sketch and the freedoms associated with design tools. There are new ways of integrating design tools and BPS tools at runtime-level have been developed, that provide performance feedback directly in the native design tool and open up for new design scenarios previously inaccessible for architects and engineers during early design stages. The integration of a design tool and a BPS tools is fundamentally changing building design into a faster, performance-aware and more flexible process, which eases the production of multiple design alternatives (Negendahl, 2015).

Automated Building Performance Simulation relies on the use of original contained in architects' models, HVAC design data, equipment performance data, applicable codes and standards. It also relies on the data conversion rules, in order to convert the BIM model to the energy model, embedded in software (Bazjanac, IFC BIM-based Methodology for Semi-automated Building Energy Performance Simulation, 2008). The aim here is to ensure that BPS tools are able to interoperate with BIM authoring software, then much of the required data model be automatically and seamlessly generated and the power of simulation embedded within the design process (Clarke \& Hensen, 2015).

\subsection{A Brief History of Automated BPS}

A major change in which data for building energy modelling is processed and analysed, in the past almost two decades both Autodesk and Bentley acquired companies with energy modelling capabilities. Autodesk acquired Revit Technologies in 2002, injecting its company into the building information modelling industry, and acquired Green Building Studio in 2008. Green Building Studio is Autodesk's web-based energy modelling tool that uses a gbXML format and runs a DOE-2.2 engine. The gbXML incorporated as a California public non-profit in 2009, assuming the name Open Green Building XML Schema, Inc., and is now the most widely used format for data transfer between BIM and BPS programs. A number of programs offer plug-in analysis tools for BIM software (Tupper, et al., 2007). Autodesk offered Revit, Revit Conceptual Energy Analysis, and Autodesk Project Vasari. Conceptual Energy Analysis and Project Vasari are the first Building Information Modelling (BIM) tools to directly export to DOE-2 and EnergyPlus. Bentley acquired Hevacomp in 2008, initially allowing it to incorporate mechanical system sizing into its BIM package. Hevacomp also provided building energy modelling, running EnergyPlus. Bentley currently offers Hevacomp Dynamic Simulation (IBPSA-USA, 2012; Bentley Systems Incorporated, 2016). True performance simulation must recognise the complex and multi-criteria nature of the building design activity and will require the inclusion within BPS of support constructs such as problem decomposition, automatic performance assessment, and standard approaches to the judging of designs in terms of diverse criteria. Until BIM matures, all that can be done to avoid an unnecessary burden on BPS tool users is to encourage vendors to adhere to common input formats and provide support for inter-tool data exchange in specific cases (Clarke \& Hensen, 2015).

\subsection{Obstacles to the automation of Building Performance Simulation}

There are numerous researches of BIM integrated BPS, however there are only a few researches have emphasised on the BPS of adaptive building information models. Kim, Asl, and Yan (2015) proposed a methodology to analyse energy performance of buildings with complex kinetic facades (Kim, Asl, \& Yan, 2015). The authors developed a method to define the appropriate movement system of 
complex kinetic shading devices and the solar incidence angle in a parametric model. The authors also used an example of complex kinetic facades, examined a responsive façade system applied to the Al Bahr Tower in Abu Dhabi, designed by Aedas UK. A complex kinetic facades control system was developed by utilising Dynamo. In this study, the complex facades vary by manipulating the opening ratio of each curtain panel in order to adjust solar heat gain. The authors chose to use Green Building Studio (GBS), a cloudbased service that allows users to run building performance simulations to optimize energy efficiency and to work toward carbon neutrality in the early conceptual phase of the design process (Egger, Autodesk Green Building Studio, 2015), in order to convert the BIM model to the energy model for the case study. However, GBS cannot recognise the complex panel as a shading device and GBS does not provide the way to calculate complex shading geometry and the hourly energy analysis results, but the author did not provide more of information on this issues. Thus, the authors had to simplify the complex panel geometry but maintain the same opening ratio and exported the energy model as the DOE2.2 input file to obtain energy simulation results using eQUEST. Otherwise, the geometry of the complex panel had been changed dramatically but the opening ratios of the simplified panels were maintained to be equal to their complex counterparts. In order to simulate the performance of building integrated kinetic photovoltaic façades, obtaining the simulation results just emphasised on the building energy consumption was not sufficient for designers. Because a kinetic photovoltaic façade was performing two tasks at the same time, generating electricity and protecting the building from the direct sun light. To predict the performance of the kinetic PV façade system, there were two BPS environments needed e.g., a BPS to investigate the influence on the energy demand (heating, cooling, and electricity) of the prototype, and the second, a BPS to analyse the solar electricity production throughout the year (Nagy, et al., 2016). Simplified BPS are fast but only provide simplified feedback while more advanced BPS are too difficult and often too slow to be used by building designers who are not experienced building energy modellers. Furthermore, only a fraction of these BPS can be used in automated processes required to perform building energy optimisation, and it is unable to be successfully achieved if the available tools do not provide seamless model exchange and full geometrical representation (Attia, De Herde, Gratia, \& Hensen, 2013; Negendahl, 2015). Coupling building performance simulation and decision support techniques to architectural geometrical modelling tools is crucial (Attia, De Herde, Gratia, \& Hensen, 2013).

\subsection{Methods}

This study aimed to explore the limitations of the automated BPS of an adaptive BIPV case study that its development conducted through a collaboration of a BIM software, Autodesk Revit, a BIM-integrated visual programming environment, Dynamo, and Autodesk Green Building Studio, web-based energy analysis. This is an initial study aimed to explore the automation of the BPS focusing on the interoperability and geometrical integration between different kinds of applications; a computer program, a software plugin, and a cloud-based tool.

\subsection{The Case Study}

To test the proposed method, there were two steps of creating a prototype to be used as the case study. Firstly, a BIM model of a building implemented a kinetic PV façade (KPVF) system has been developed. The tested building located in Bangkok, Thailand $\left(13.733^{\circ} \mathrm{N}, 100.5^{\circ} \mathrm{E}\right)$. It was a simple rectangle-shaped single story building that had 6.00 meters length, 4.00 meters width, and 4.00 meters height. The modelled building had a Thailand-standard construction with brick-plaster walls and cast-in-situ concrete floor and slab roof.

Table 1. Summarises the input parameters used in Autodesk Revit

\begin{tabular}{ll}
\hline Building Components & \\
\hline Building floor and slab roof & Cast-in-situ $100 \mathrm{~mm}$ \\
Building walls & Brick wall $100 \mathrm{~mm}$ \\
Thermal set points & Cooling $28^{\circ}$, No heating \\
Building Operating Schedule & Hospital - Nursery - Hospital/Healthcare: 8 AM to 9 PM \\
Material Thermal Properties & Detailed Elements, where enabled and where material \\
& properties are specified for building elements, override both \\
& conceptual types and schematic types (Autodesk, 2016) \\
Weather data & Bangkok, Thailand (weather station: 621814 ) \\
\hline
\end{tabular}

\subsection{Descriptions of KPVF}

This study examined a kinetic photovoltaic façade system by imitating the style of the top half of the Kiefer showroom's dynamic façade system designed by Giselbrecht + Partner ZT GmbH (Zvironaite, Knol, \& Kneepens, 2014). Kiefer Technic was an office building and exhibition space in Austria. The dynamic façade system changed to outdoor conditions, optimising internal climate. The façade system operated on electronic shutters of perforated aluminium panels that can fold in various positions allowing occupants to adjust the light or temperature in the building. (Vergauwen \& Temmerman, 2012; Radwan, 2013). In this study, the KPVF system had been developed following methods proposed by Jeremy Roh (2015) (Roh, 2015). These methods including the development of a parametric KPVF curtain panel family and a prototype of building integrated KPVF using Autodesk Revit, and the parametric model scripting in Dynamo. The dimensions of KPVF and its geometries have been illustrated in Fig. 2. The materials of the top half of the KPVF have been assumed to be photovoltaic modules for electric power generation. 


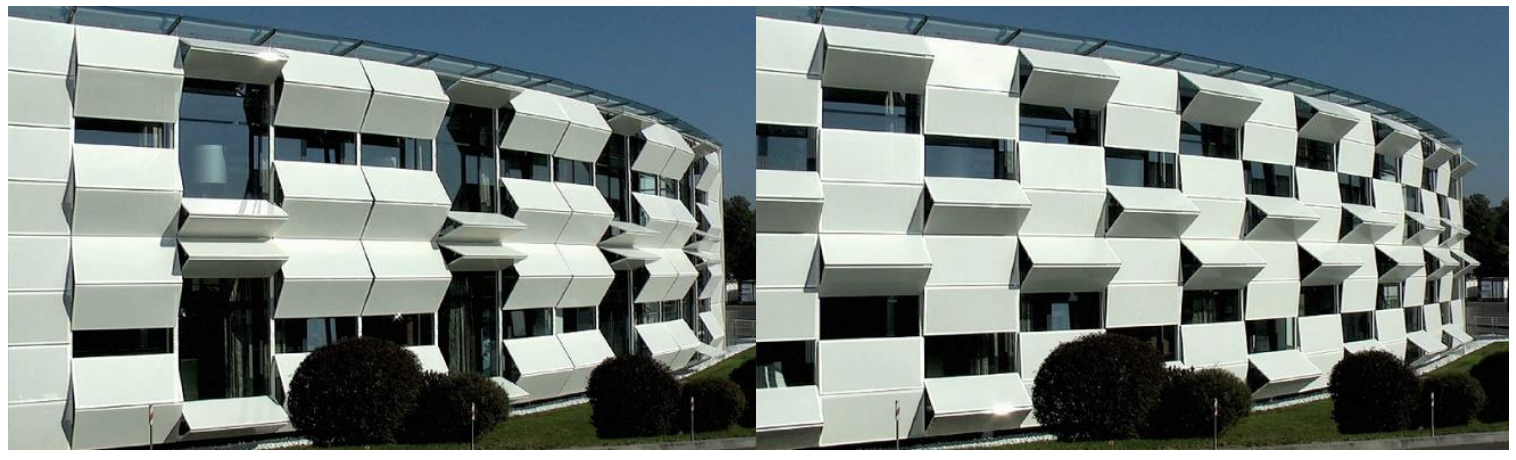

(a)

(b)

Fig. 1. (a) and (b) Kiefer Technic Showroom's dynamic façade system that changes to outdoor conditions

\subsection{Development of KPVF family in Autodesk Revit}

A folding panel has been developed using the Family Editor, an authoring environment in Autodesk Revit is where the users create the component families. This folding panel was a curtain panel family with adaptive parameters that allowed the panel to change its geometry following the changing of the rotation angle parameter. Fig. 2. illustrates the created family of the KPVF in the Family Editor

\subsection{KPVF Control System}

The concept of kinetic PV façade's movement was the variations of KPVF generated by manipulating the rotation angle of each curtain panel to be perpendicular to solar altitude. The inner angle rotated up and down, it was always going to be equal to the altitude of the sun (the sun angle), by reason of the amount of solar radiation incident on a tilted module surface was the component of the incident solar radiation which was perpendicular to the solar module surface of the KPVF. When the absorbing surface and the sunlight were perpendicular to each other, the power density on the surface was equal to that of the sunlight (in other words, the power density will always be at its maximum when the PV module is perpendicular to the sun) (Honsberg \& Bowden, 2014). When a panel became in affect with the sun direction, the KPVF initiated to adapt blocking the sun. The incidence angle was the angle between the Sun's direction vector and the normal vector of a surface, the incidence angle on a given surface was employed to define the rotation angle through the movement of the kinetic photovoltaic façade. When the incidence angle on a surface was equal to or larger than $90^{\circ}$ which meant there was no direct solar radiation, the KPVF was fully open (the rotation angle equals to $85^{\circ}$ ). When the incidence angle was 0 means that the surface's normal was parallel with the sun's direction, then the panel was fully closed. The variation of the KPVF has been changed based on the incidence angle of each panel. The value to define, the rotation angle from $0^{\circ}$ to $85^{\circ}$, which made the panel fully closed to fully open, respectively (Kim, Asl, \& Yan, 2015). Appling the KPVF in the prototype, the building had curve-shape panels all four sides of the prototype to be the bases for the KPVFs, these curve panels providing a variation of KPVF's normal vectors across the façades.

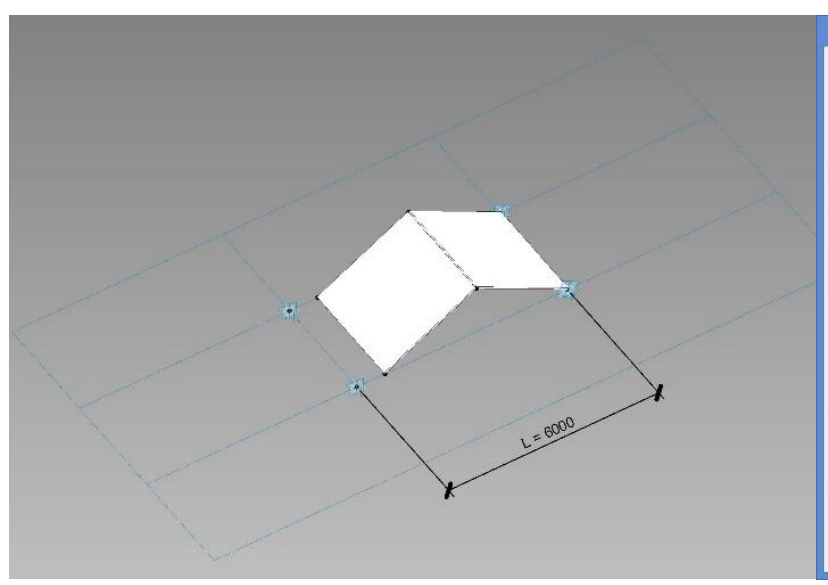

(a)

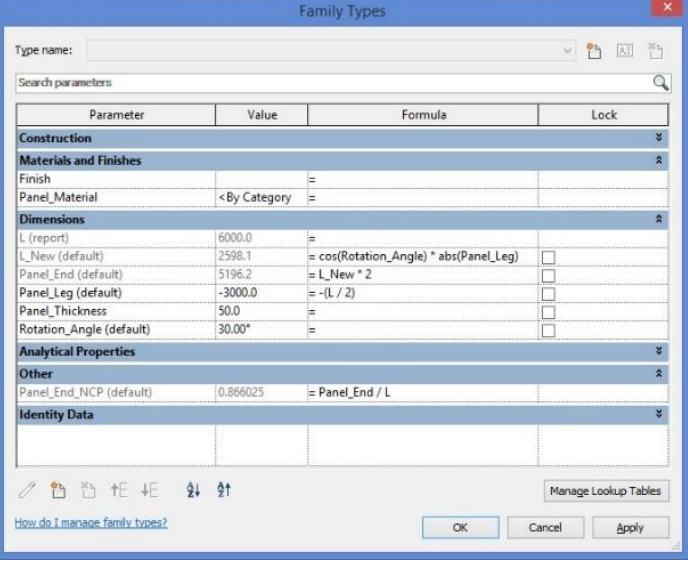

(b)

Fig. 2. (a) Folding Panel Family: A Kinetic Photovoltaic Façade (KPVF); (b) Family Types of Folding Panel 


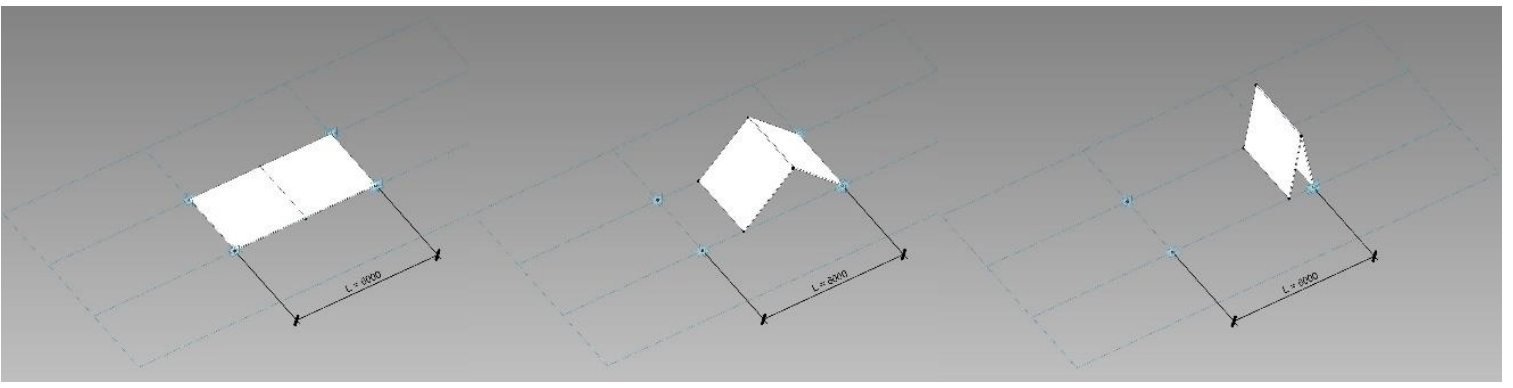

(a)

(b)

(c)

Fig. 3. Folding Panel (a) Rotation Angle $=0^{\circ}$; (b) middle: Rotation Angle $=45^{\circ}$; (c) right: Rotation Angle $=85^{\circ}$

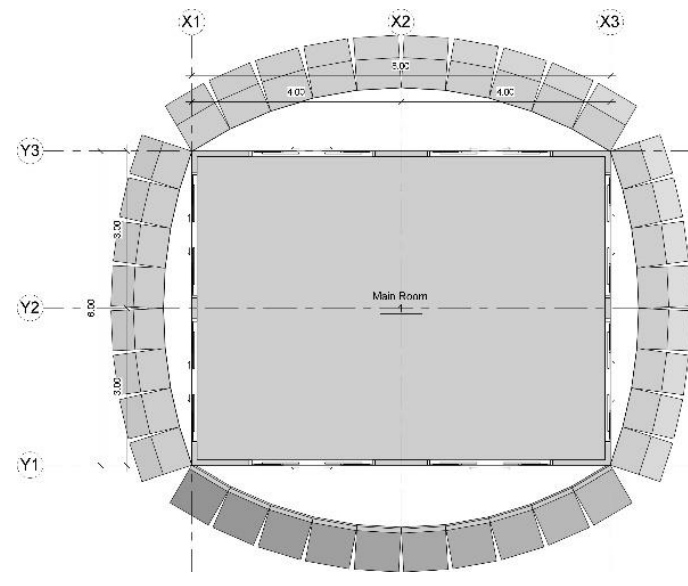

(a)

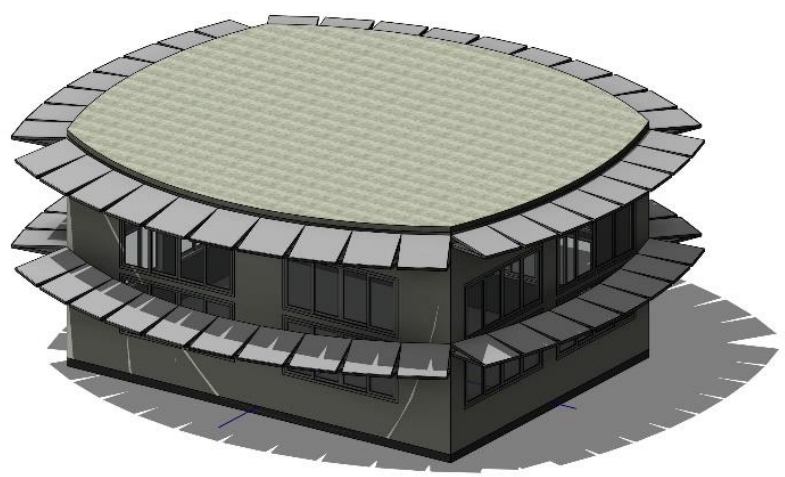

(b)

Fig. 4. The KPVF applied in the prototype (a) floor plan view, (b) isometric view

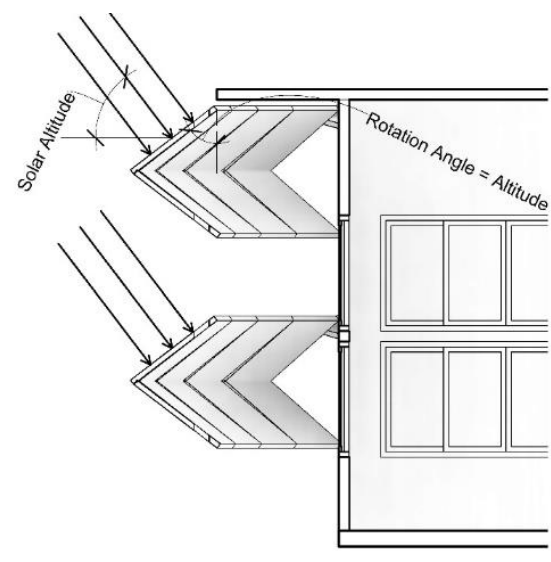

(a)

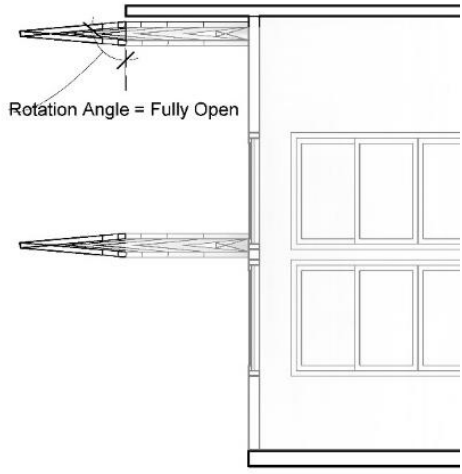

(b)

Fig. 5. (a) KPVF when sun in affect; (b) KPVF when sun is not in affect

\subsection{Implementation of KPVF Control}

In this study, the KPVF control system is developed by using Dynamo, an open source visual programming add-in for Autodesk Revit for computational design, it provided an accessible method of using environmental parameters to control building information models via scripting interface (Autodesk, 2014; Kensek, 2014). The concept of scripting in Dynamo is; the elements with which users interact in Dynamo are referred to as "nodes". Each node can have a number of "ports", which enable communication between nodes along "connectors". Ports can only be connected to other ports whose output type matches the port's input type, or to any port whose output type is further up the inheritance hierarchy of the port's input type. Together these connected elements create the "workflow" (Kensek, 2014). 


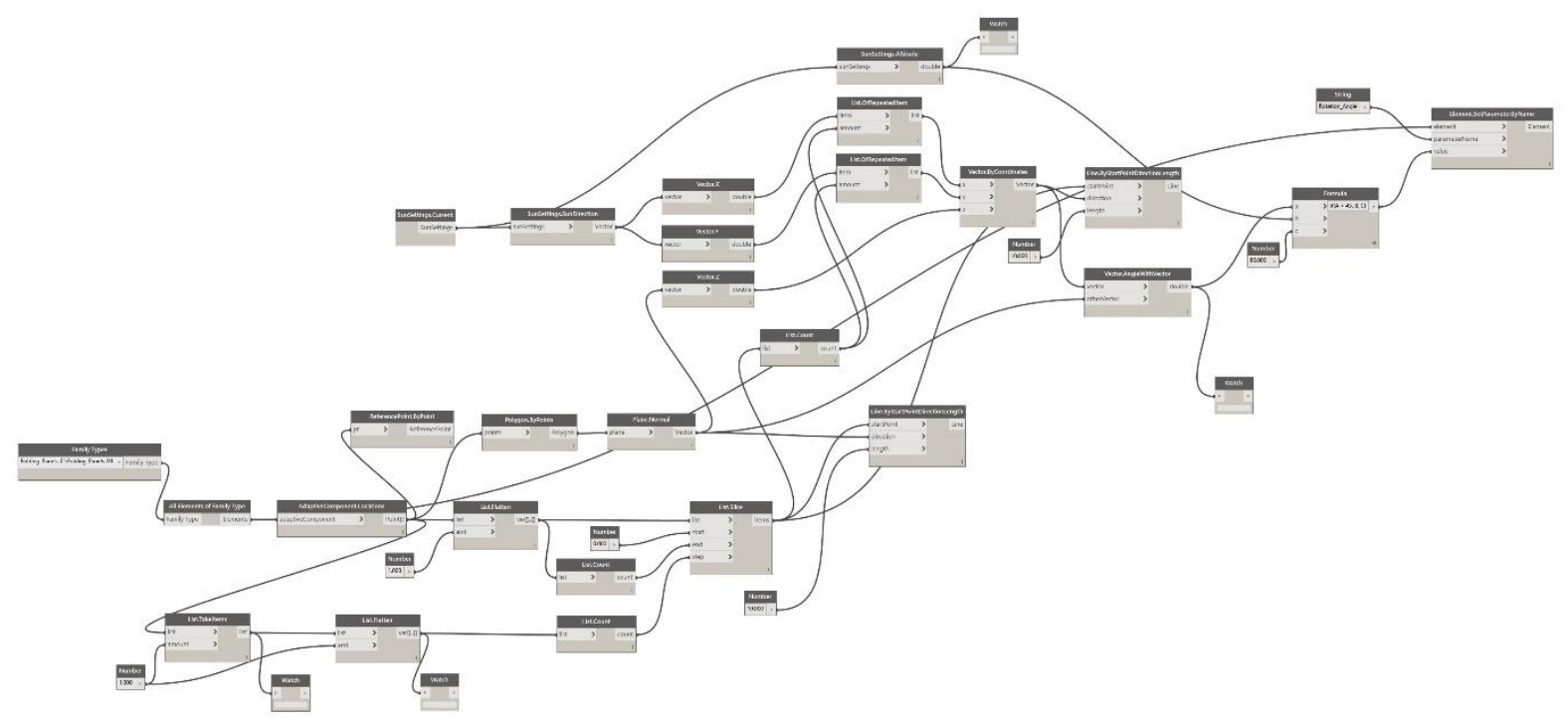

Fig. 6. A visual programming script to control the KPVF

\subsection{Testing of the automated BPS of a KPVF case study}

There are two types of available BPS tools offered by Autodesk to be used with Revit; external to Revit, and within Revit but for the latest version of Revit, Revit 2017, most of tools within Revit have been replaced to be parts of Insight 360 including, solar analysis, light analysis, heating and cooling loads (Stine, 2015). To run an automated BPS for a BIM model through the collaboration of Autodesk Revit, Dynamo plugin, and The Green Building Studio (GBS) is by using Insight 360, a cloud-based tool that enabling automated building energy and environmental performance simulation which its whole building energy analysis is powered by the GBS (Egger, Autodesk Insight 360, 2015; Stine, 2015). The overall workflow for testing the automated BPS of the KPVF consisted of two parts; prototype creating using parametric modelling, and building performance simulation through automation processes.

The first part, loading the parametric curtain panel family of the KPVF into a conceptual mass environment of Autodesk Revit. Setting the location of the case study's KPVF by using the default city list: Bangkok, Thailand. Specify sun settings for solar studies, unfortunately, using the Dynamo scripts that developed for this study was unable to generate a batch geometries of the KPVF by hourly or multi-day solar study. The researcher had to set the solar study to still mode and generated the one-at-a-time KPVF geometries from 9.00 AM to 5.00 PM, hourly, for two astronomical events annually; a solstice (June 21 and December 21) and an equinox (March 20 and September 23), total 36 KPVFs for all of 36 points in time generated to validate the Dynamo scripts. Then loading these generated KPVFs into the Revit project environment to combine them with the case study building, the prototype created, no errors and warnings that provided from automatic detection of design-related errors from the BIM authoring software. The prototypes with the KPVF at 1 PM, December 21 and 9 AM, September 22 have been selected to create an energy model for Insight generating. In this study, three modes of creating the Energy Analytical Model (EAM) have been separately chosen to test how the automated BPS did generate the EAMs; Use Conceptual Masses, Use Building Elements, and Use Conceptual Masses and Building Elements.

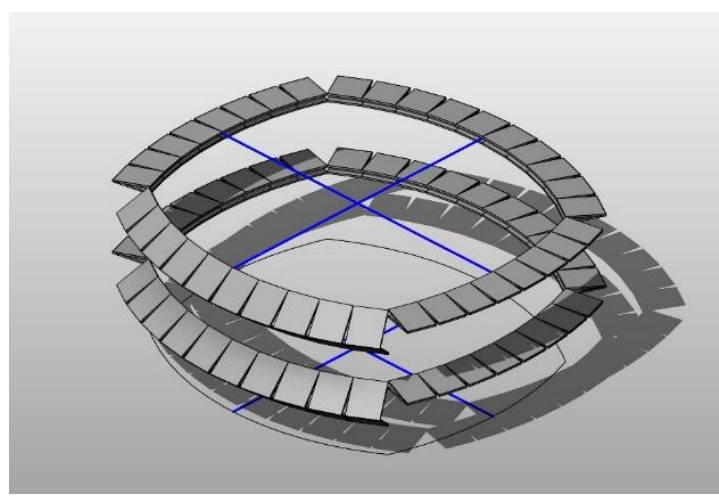

(a)

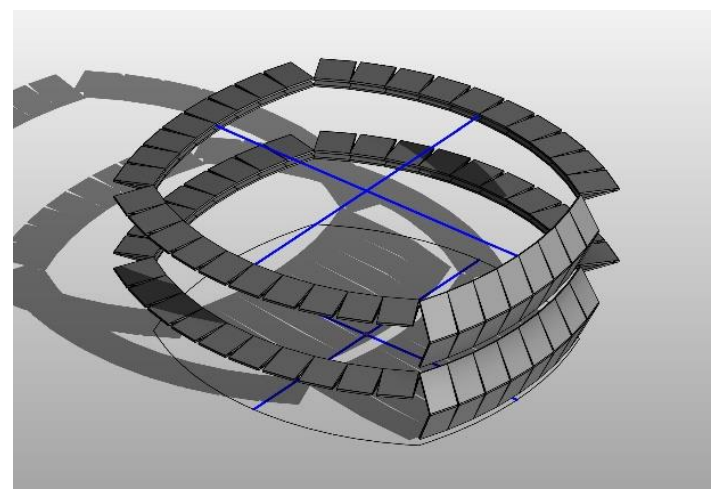

(b)

Fig. 7. The prototypes' kinetic PV façades at (a) 1 PM, December 21 (winter solstice)

(b) 9 AM, September 22 (Fall Equinox) in conceptual mass environment 

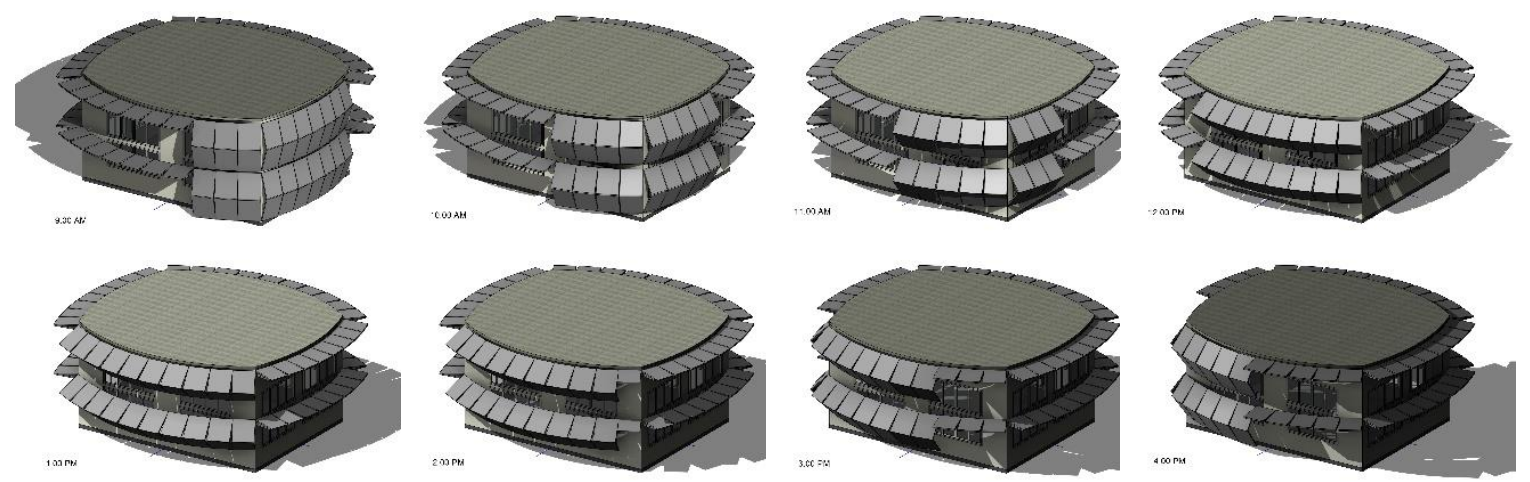

Fig. 8. The prototype's kinetic PV façades from 9 AM to 4 PM, December 21 (winter solstice)

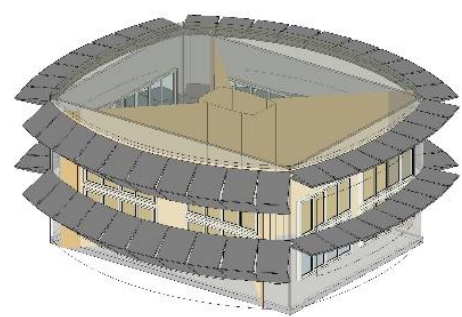

(a)

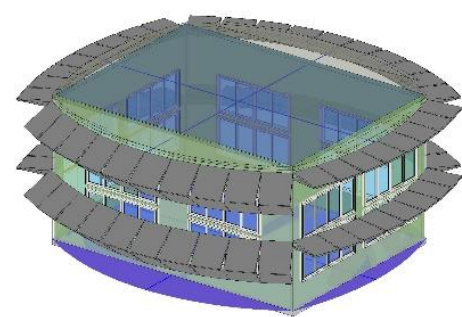

(b)

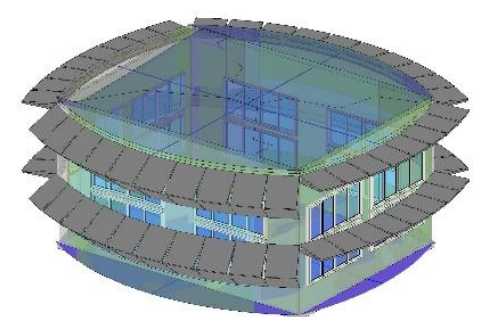

(c)

Fig. 9. The Energy Analytical Models (EAMs) of 1 PM, December 21 (winter solstice) (a) Use Conceptual Masses; (b) Use Building Elements; (c) Use Conceptual Masses and Building Elements

The second part, using Insight 360 was a fully automatic cloud-based BPS. This tool will send the energy analysis model (EAM) to the Autodesk A360 cloud for simulation. Thus, after finishing "generate Insight" for all the three modes of the EAMs without any simplification of the prototypes' geometries, users just waiting for the system to send the notifications by email then launch Insight 360 via the links attached in the emails for interactive project exploration (Stine, 2015).

\subsection{Results}

Once an analysis has been performed, the results can be seen by clicking the links in the emails or selecting the Insight 360 tool within Revit. For the Insight results of the "Use Conceptual Masses mode" EAM, obviously, the Insight results of both models; 1 PM, December 21 and 9 AM, September 22, were identical, looking at the Benchmark Comparison tile, the high and low possible cost range has been shown that meant the best and worst possible scenarios based on energy usage. The current annual energy cost/usage per square meter was $24.8 \mathrm{USD} / \mathrm{m}^{2} /$ year and $342 \mathrm{kWh} / \mathrm{m}^{2} /$ year for both models. For the Insight results of the "Use Building Elements" and "Use Conceptual Masses and Building Elements" EAMs, the Insight results of both models; 1 PM, December 21 and 9 AM, September 22, were also identical, as well. The current annual energy cost/usage per square meter was 30 USD $/ \mathrm{m}^{2} / \mathrm{year}$ and $412 \mathrm{kWh} / \mathrm{m}^{2} /$ year for the four models.

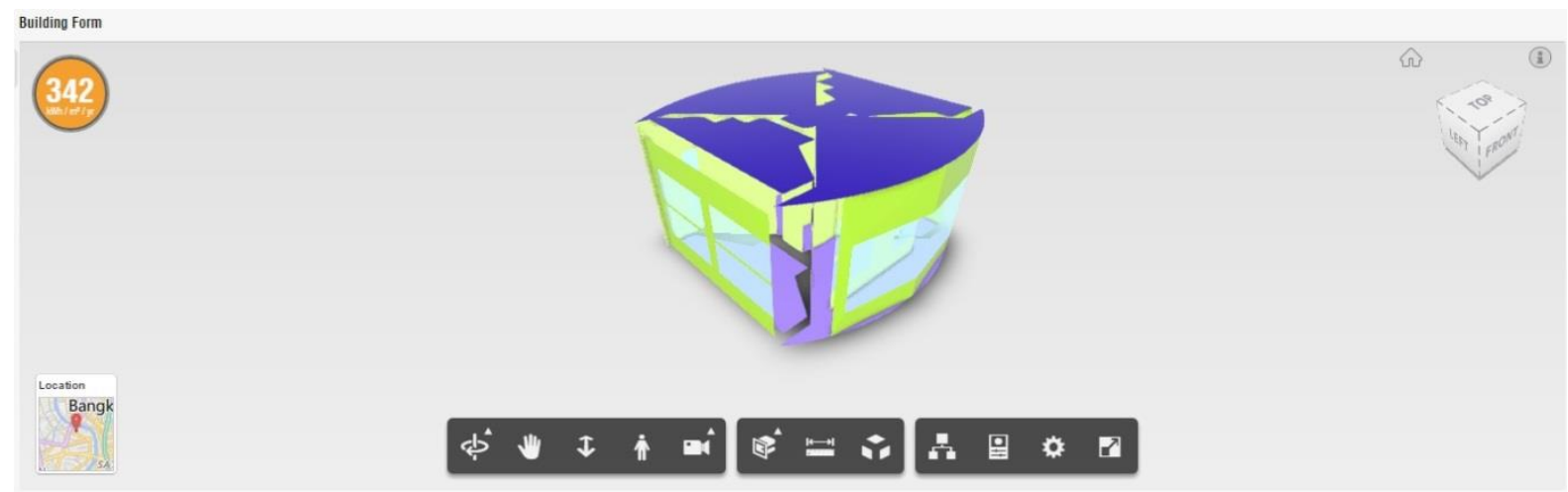

Fig. 10. The initial project view in Insight 360 shows the current annual energy usage, location, Energy Analysis Model (EAM) toolbar, and the Insight generated EAM of the prototype (Use Conceptual Masses mode) 


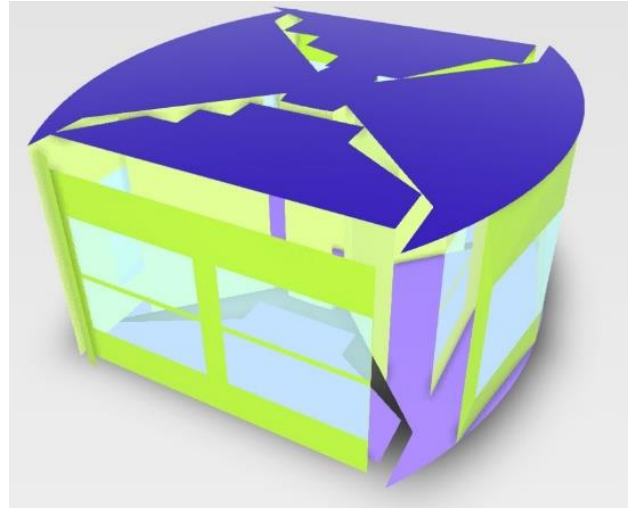

(a)

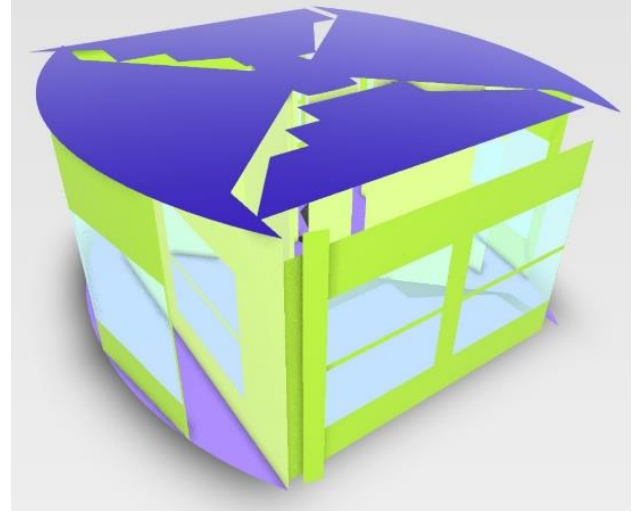

(b)

Fig. 11. The Insight generated EAM of the prototype (Use Conceptual Masses mode)

(a) view from the South-East; (b) view from the South-West

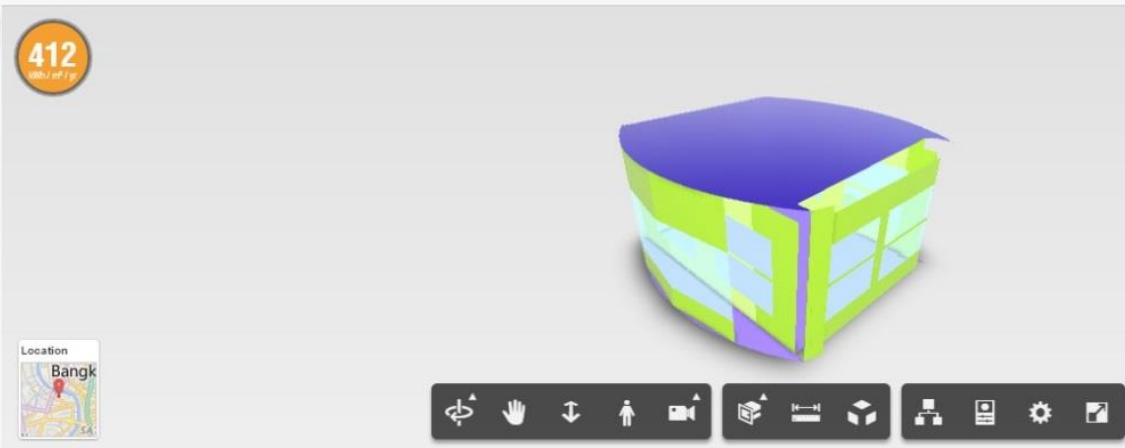

Fig. 12. The initial project view in Insight 360 of the Insight generated EAM of the prototype both Use Building Elements, and Use Conceptual Masses and Building Elements modes

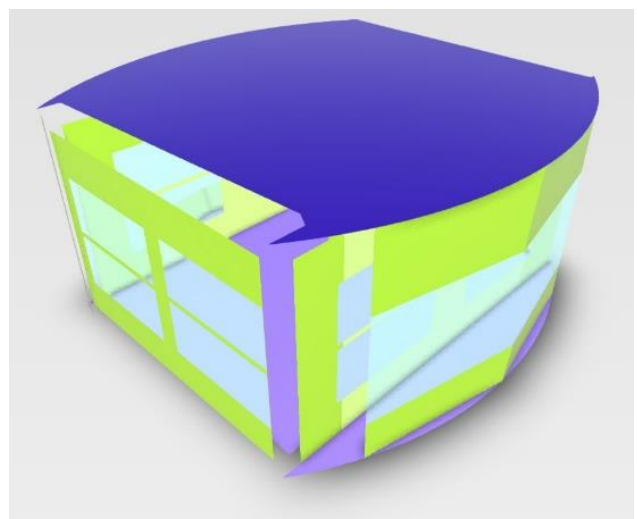

(a)

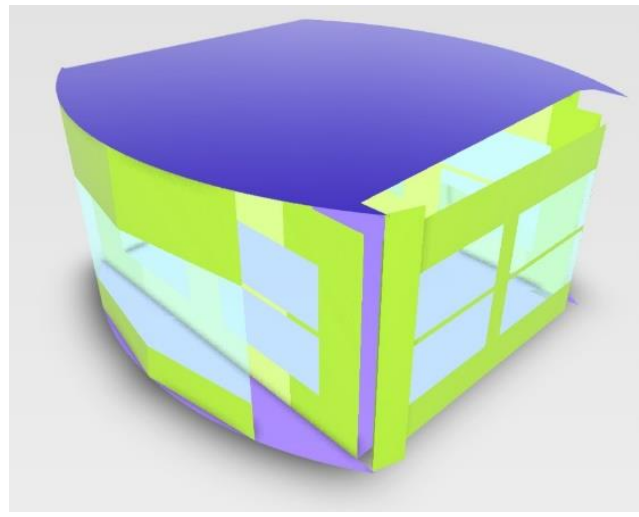

(b)

Fig. 13. the Insight generated EAM of the prototype (Use Building Elements, and Use Conceptual Masses and Building Elements modes) (a) view from the South-East; (b) view from the South-West

On the first glance the EAM geometries generated with Insight 360 appeared completely different from the original prototype models. All of the three EAMs did not show any of the KPVF geometries and most of the geometries in the EAM were broken, distorted, and misplaced, especially the EAM that generated from the Use Conceptual Masses and Building Elements mode as shown in Fig. 10 and Fig. 11. During all the processes and repetitions of using the Insight 360 there was no warnings and error notifications from the systems. Evidently, the Insight 360 completely ignored to generate and include all of the KPVF geometries into the calculations, in consequence, these automated BPS results might be unreliable by themselves. 


\subsection{Discussion}

The utilisation of BIM for building performance modelling and analysis is an increasing research topic in the academic community, due to the BIM potentials for integration of the geometrical, material, technical, structural, and HVAC data on the other hand, as well as stricter requirements and policies for sustainable construction on the other. Several tools have already been introduced for BIM-based and BIM-supported automated energy analysis (Gourlis \& Kovacic, 2017). Interoperability and data-transfer as well as ease of use from BIM to BPS systems has been becoming important parts in order to reduce the re-modelling efforts, easy creation of Energy Analytical Models (EAMs) and effortless usage of the automated BPS (Bazjanac, IFC BIM-based Methodology for Semi-automated Building Energy Performance Simulation, 2008; Gourlis \& Kovacic, 2017). The results from the experiments on the automated building performance simulations revealed that there were problems in data transferability and software interoperability such as erroneous geometries of the EAMs gave rise to questionable or unreliable results. Building Performance Simulation (BPS) models, as used in building design, can generally be classified as both prognostic law-driven (or forward) models, they are used to predict the behaviour of a complex system given a set of well-defined laws, and data-driven (or inverse) models that referred to methods which used monitored data from the building to produce models which are capable of accurately predicting system behaviour (Coakley, Raftery, \& Keane, 2014). The automated BPS would be considered as Black-box approach, an approach subcategorized of the datadriven approach, which is advantageous in providing very short development time for the users but it needs extensive training data for performance prediction and there is no explicit link between model inputs and physical building parameters. Thus, it is impossible to extrapolate model to compute effect of design or operational changes. What's in the black box as important, if not more important, than the interface and results (Crawley, 2015) that would be problematic for the building designers who are inexperienced BPS users. Step-by-step and customizable interfaces or a detailed software wizard of the automated BPS would help to reduce the errors and increase quality and reliability of the results.

Typically, the use of BPS to predict energy consumption during building operation requires calibrating the building energy model or the EAM to be as close as possible to how the building will actually be built, occupied and operated (Summerfield \& Lowe, 2012; Reeves, Olbina, \& Issa, 2015). It was fortunate that the automated BPS workflow experimented in this study allowed users to finely tune the inputs to calibrate the energy model with lots of pre-computed DOE 2.2 whole building energy simulations that represent all worldwide climate zones and a wide range of typical building forms, functions and efficiency (Egger, Autodesk Insight 360, 2015) during the BIM models development and the EAM generations.

These obstacles to the automation of BPS in adaptive BIPV design occurred from these Black box processes posed what Bazjanac (2011) mentioned to the "Owner's dilemma" that how do the owners want the BPS for? To acknowledge the actual performance of the simulated buildings or to acquire the results that their businesses required; which modeller does the client choose to continue the modelling and simulation? Or the modeller with the lowest cost of service? Or the one who promises the shortest simulation execution, analysis and finding delivery schedules? (Bazjanac, et al., 2011)

\subsection{Conclusions}

In this paper, the authors demonstrated the creation of an adaptive building prototype using a parametric modelling tool to generate and control the adaptations of the building information models, and explored the initial limitations of the automated BPS of an adaptive BIPV case study that its development conducted through a collaboration of a BIM software, a BIM-integrated visual programming environment, and a cloud-based energy analysis tool. The obstacles to the interoperability and geometrical integration on automated BIM-BPS workflow have been fundamentally revealed. Though the results of this study reached just the errors of the prototypes' geometries, however these results confirmed the Black-box approach that the building designers should take into consideration.

\section{References}

Agugiaro, G. (2016). Energy planning tools and CityGML-based 3D virtual city models: experiences from Tento (italy). Applied Geomatics, Volume 8, Issue 1, 41-56.

Attia, S., De Herde, A., Gratia, E., \& Hensen, J. L. (2013). Achieving informed decision-making for net zero energy buildings design using building performance simulation tools. Building Simulation, 6(1), 3-21.

Autodesk. (2013). Dynamo: Visual Programming for Design. Retrieved from Autodesk University: http://aucache.autodesk.com/au2013/sessionsFiles/3362/1916/handout_3362_Dynamo\%20Visual\%20Programming\%20for\%20Design.pdf

Autodesk. (2014, November 02). Where to locate and download Dynamo for Autodesk Revit. Retrieved from Autodesk Knowledge Network: https://knowledge.autodesk.com/support/revit-products/troubleshooting/caas/sfdcarticles/sfdcarticles/Where-to-locate-and-download-Dynamo-for-Autodesk-Revit.html

Autodesk. (2016). Advanced Energy Settings. Retrieved from Autodesk Revit 2017: http://help.autodesk.com/view/RVT/2017/ENU/?guid=GUID-24528ACB-E82C-410FBEB7-24BDBA6D0769

Bazjanac, V. (2008). IFC BIM-based Methodology for Semi-automated Building Energy Performance Simulation. CIB-W78 25th (p. 15). Santiago, Chile: Lawrence Berkeley National Laboratory.

Bazjanac, V., Maile, T., Rose, C., O'Donnell, J. T., Mrazovic, N., Morrissey, E., \& Welle, B. R. (2011). An assessment of the use of Building Energy Performance Simulation in early design. Proceedings of Building Simulation 2011 (pp. 1579-1585). Sydney: International Building Performance Simulation Association. 
Bentley Systems Incorporated. (2016). Hevacomp Dynamic Simulation. Retrieved from Bentley: https://www.bentley.com/en/products/product-line/building-designsoftware/hevacomp-dynamic-simulation

Clarke, J. A., \& Hensen, J. L. (2015). Integrated building performance simulation: Progress, prospects, and requirements. Building and Environment, 91, 294-306.

Coakley, D., Raftery, P., \& Keane, M. (2014). A review of methods to match building energy simulation models to measured data. Renewable and Sustainable Energy Reviews, 123-141.

Crawley, D. B. (2015, November 10). Building Performance Simulation: What's in the Black Box \& How Do I Get My BIM Data There? Retrieved from U.S. Green

Building Council, Texas Gulf Coast Region: http://usgbctexasgulfcoast.org/images/downloads/151110crawley_building_performance_simulation_whats_in_the_black_box_and_how_do_i_get_bim_in_there.pd

Eastman, C., Teicholz, P., Sacks, R., \& Liston, k. (2011). BIM Handbook - A Guide to Building Information Modeling for Owners, Managers, Designers, Engineers, and Contractors. Hoboken, New Jersey: John Wiley \& Sons, Inc

Egger, S. (2015, December 23). Autodesk Green Building Studio. Retrieved from Building Energy Software Tools: http://www.buildingenergysoftwaretools.com/software/autodesk-green-building-studio

Egger, S. (2015, December 23). Autodesk Insight 360. Retrieved from BEST Directory: Building Energy Software Tools: http://www.buildingenergysoftwaretools.com/software/autodesk-insight-360

Fiorito, F., Sauchelli, M., Arroyo, D., Pesenti, M., Imperadori, M., Masera, G., \& Ranzi, G. (2016). Shape morphing solar shadings: A review. Renewable and Sustainable Energy Reviews, 55, 863-884.

Frontini, F., Bonomo, P., Chatzipanagi, A., Verberne, G., Van Den Donker, M., Sinapis, K., \& Folkerts, W. (2015). BIPV Product Overview for Solar Facades and Roofs. Retrieved from The Solar Energy Application Centre (SEAC): http://www.seac.cc/fileadmin/seac/user/doc/SEAC-SUPSI_report_2015_BIPV_product_overview_for_solar_facades_and_roofs_1_.pdf

Gourlis, G., \& Kovacic, I. (2017). Building Information Modeling for analysis of energy efficient industrial buildings - A case study. Renewable and Sustainable Energy Reviews, 68, 953-963.

Hand, J. W., Crawley, D. B., Donn, M., \& Lawrie, L. K. (2005). Improving the data available to simulation programs. Proceedings of Building Simulation 2005 (pp. 373 380). Montreal, Canada: International Building Performance Simulation Association (IBPSA).

Honsberg, C., \& Bowden, S. (2014). Solar Radiation on a Tilted Surface. Retrieved from PV EDUCATION.ORG: http://www.pveducation.org/pvcdrom/propertiessunlight/solar-radiation-tilted-surface

IBPSA-USA. (2012, September 13). History of Building Energy Modeling. Retrieved from BEMBook: http://bembook.ibpsa.us/index.php/History_of_Building_Energy_Modeling

Ibraheem, Y., Farr, E. R., \& Piroozfar, P. A. (2016). Embedding passive intelligence into building envelopes: a review of the state-of-the-art in integrated photovoltaic shading devices. 8th International Conference on Sustainability in Energy and Buildings, SEB. Turin, Italy: Energy Procedia.

Jelle, B. P., Breivik, C., \& Røkenes, H. D. (2012). Building integrated photovoltaic products: A state-of-the-art review and future research opportunities. Solar Energy Materials \& Solar Cells, 69-96.

Kensek, K. M. (2014, October). Integration of Environmental Sensors with BIM: case studies using Arduino. Dynamo, and the Revit API. Informes de la Construcción, 66(536), 31-39. doi:10.3989/ic.13.151

Kim, H., \& Anderson, K. (2013). Energy modeling system using building. Journal of Computing in Civil Engineering 27(3), 203-211.

Kim, H., Asl, M. R., \& Yan, W. (2015). Parametric BIM-based Energy Simulation for Buildings with Complex Kinetic Facades. Proceedings of the 33rd eCAADe Conference. 1, pp. 657-664. Vienna, Austria: Education and research in Computer Aided Architectural Design in Europe.

Kron, Z. (2013, December 5). Enhanced Parametric Design with Dynamo Visual Programming for Revit and Autodesk Vasari. Retrieved from Autodesk University: http://au.autodesk.com/au-online/classes-on-demand/class-catalog/2013/revit-for-architects/ab3362-I

Krygiel, E., \& Nies, B. (2008). Green BIM: Successful Sustainable Design with Building Information Modeling. New Jersey: John Wiley \& Sons.

Kumar, S. (2008). Interoperability between building information models. Los Angeles, USA: PhD Thesis, University of Southern California.

Kymmell, W. (2008). Building Information Modeling: Planning and Managing Construction Projects with 4D CAD and Simulations . New York: McGraw-Hill.

Ladenhauf, D., Battisti, K., Berndt, R., Eggeling, E., Fellner, D. W., Gratzl-Michlmair, M., \& Ullrich, T. (2015). Computational geometry in the context of building information. Energy and Buildings, 115, 78-84.

Matthew, G., Jason, G., Melissa, T., Seokho, C., \& Fiona, C. Y. (2013). Building Information Modelling : an international survey. Building Information Modelling : an international survey. In World Building Congress 2013, 5-9 May 2013. Brisbane, QLD: Queensland University of Technology.

Nagy, Z., Svetozarevic, B., Jayathissa, P., Begle, M., Hofer, J., Lydon, G., . . Schlueter, A. (2016). The Adaptive Solar Facade: From concept to prototypes. Frontiers of Architectural Research, 5, 143-156.

Negendahl, K. (2015). Building performance simulation in the early design stage: An introduction to integrated dynamic models. Automation in Construction, 54, 39-53. 
O'Donnell, J., See, R., Rose, C., Maile, T., Bazjanac, V., \& Haves, P. (2011). Simmodel: A domain data model for whole building energy simulation. SimBuild 2011. Sydney, Australia: International Building Performance Simulation Association (IBPSA).

Peng, C., Huang, Y., \& Wu, Z. (2011). Building-integrated photovoltaics (BIPV) in architectural design in China. Energy and Buildings, 3592-3598.

Pesenti, M., Masera, G., Fiorito, F., \& Sauchelli, M. (2015). Kinetic solar skin: a responsive folding technique. Energy Procedia, 70, 661-672.

Radwan, A. H. (2013). Smart Facades: From adaptation with climate, changing esthetical values, till digital drawings on buldings envalope. Retrieved from Academia.edu: $\quad$ http://s3.amazonaws.com/academia.edu.documents/41020030/03_SMART_FACADESCopy.pdf?AWSAccessKeyld=AKIAJ56TQJRTWSMTNPEA\&Expires=1481256486\&Signature=EMuXHPZ8MSWvVT\%2BqOyjxANBZwyE\%3D\&response-contentdisposition=inline\%3B\%20filename\%3DSmart_Facades_From_adap

Reeves, T., Olbina, S., \& Issa, R. R. (2015). Guidelines for using Building Information Modeling for energy analysis of buildings. Buildings, 5, 1361-1388. doi:doi:10.3390/buildings5041361

Reinhard, P., Chirilă, A., Blösch, P., Pianezzi, F., Nishiwaki, S., Buecheler, S., \& Tiwari, A. N. (2013). Review of Progress Toward 20\% Efficiency Flexible CIGS Solar Cells and Manufacturing Issues of Solar Modules. IEEE Journal of Photovoltaics, 3(1), 572-580. doi:10.1109/JPHOTOV.2012.2226869

Roh, J. (2015, March 05). 20150305 Turorial Dynamo Folding Panel Sun Script. Retrieved from Youtube.com: https://www.youtube.com/watch?v=odgFpKVmdhM

Shen, Y. T., \& Lu, P. W. (2016). The development of kinetic facade units with BIM-based active control system for the adaptive building energy performance service. International Conference of the Association for Computer-Aided Architectural Design Research in Asia CAADRIA 2016 (pp. 517-526). Hong Kong: The Association for Computer-Aided Architectural Design Research in Asia (CAADRIA).

Stine, D. (2015, November 20). Building Performance Analysis in Revit 2016 R2 with Autodesk Insight 360. Retrieved from AECbytes: http://aecbytes.com/tipsandtricks/2015/issue76-revit.html

Strong, S. (2011, December 27). Building Integrated Photovoltaic (BIPV). Retrieved July 25, 2015, from Whole Building Design Guide: http://www.wbdg.org/resources/bipv.php

Summerfield, A. J., \& Lowe, R. (2012). Challenges and future directions for energy and building research. Building Research \& Information, 40(4), 391-400.

Tupper, K., Franconi, E., Chan, C., Fluhrer, C., Jenkins, M., \& Hodgin, S. (2007, January 24). Building Energy Modeling (BEM) Innovation Summit. Retrieved from Rocky Mountain Institute: https://www.google.co.th/url?sa=t\&rct=j\&q=\&esrc=s\&source=web\&cd=1\&cad=rja\&uact=8\&ved=0ahUKEwijxP3_qoTRAhUTTY8KHWP_AQYQFggYMAA\&url=http\%3A \%2F\%2Frmi.org\%2Fcontent\%2FFiles\%2FSummit_PreRead_FINAL.pdf\&usg=AFQjCNHdOnx0XTNp1iVBu-eXJk6IJccECg\&sig2=uPNLT6hPPW6znGh

Vergauwen, A., \& Temmerman, N. D. (2012). Analysing the applicability of deployable scissor structures in responsive building skins. High Performance Structure and Materials, VI, 493-504.

Yoo, S.-H. (2011). Simulation for an optimal application of BIPV through parameter variation. Solar Energy, 85, 1291-1301.

Zvironaite, K., Knol, A., \& Kneepens, S. (2014). Kinetica: A playful way through the world of moving facades. Retrieved from Delft University of Technology: http://repository.tudelft.nl/islandora/object/uuid:cabfd871-7ea9-465a-9f78-2a24fdcb9430?collection=research 